\title{
Genetic diversity in westernmost European populations of Halimione verrucifera (M. Bieb.) Aellen
}

\author{
MIHNEA VLADIMIRESCU ${ }^{1}$, IOANA CĂTĂLINA PAICA ${ }^{1}$, CRISTIAN BANCIU ${ }^{1}$, \\ GABRIEL MIHAI MARIA ${ }^{1}$, ANCA MANOLE ${ }^{1}$
}

${ }^{1}$ Institute of Biology Bucharest, Romanian Academy, Bucharest, Romania

\begin{abstract}
Halimione verrucifera - an extreme halophyte plant species spread mainly in Asia with a few locations in South Eastern Europe - have the westernmost marginal populations in Romania. In order to asses population fitness and conservation status, genetic diversity among and within population was estimated using ISSR markers.A set of 6 primers were utilized after selection from a primer set which showed clear and reproducible banding patterns, generating a total number of 86 loci. A presence/absence matrix was generated by evaluating the gel electrophoresis banding patterns of PCR products. From this, genetic distances between individuals and populations were calculated, which were used in all subsequent generation of genetic diversity indices, assuming the Hardy-Weinberg equilibrium. Result revealed a low expected heterozygosity for both populations. Further testing by constructing an UPGMA dendrogram and a PCoA analysis confirmed that populations are clearly separated and with levels of genetic diversity that could ensure population survival in time and space.
\end{abstract}

Keywords Halimione verrucifera, genetic diversity, ISSR primers, Pâclele mari, Pâclele mici.

To cite this article: VLADIMIRESCU M, PAICA IC, BANCIU C, MARIA GM, MANOLE A. Genetic diversity in westernmost European populations of Halimione verrucifera (M. Bieb.) Aellen. Rom Biotechnol Lett. 2021; 26(2): 2541-2547. DOI: $10.25083 / \mathrm{rbl} / 26.2 / 2541.2547$

*Corresponding author: CRISTIAN BANCIU, PhD, Institute of Biology Bucharest, Romanian Academy, Plant and Animal Cytobiology Department, Spl. Independentei, 296, 060031, District 6 Bucharest, Romania, Tel: +4 021221 9092, Fax: +4 0212219071

E-mail: cristi.banciu@ibiol.ro 


\section{Introduction}

Halimione verrucifera (M. Bieb.) Aellen - saltbush is an extreme halophyte plant species occurring in saline and alkaline environments. Generic position of species was subject of controversy since it was included in successively in Atriplex, Obione, Halimus and Halimione. The most recent revision was made by Sukhorukov et al. in 2018, when based on molecular phylogenetic data and seed coat anatomy, the species was assigned to Halimione genus.

The main distribution area of $H$. verrucifera is Central and Southwestern Asia and only a few locations in South Eastern Europe (Fig. 1).

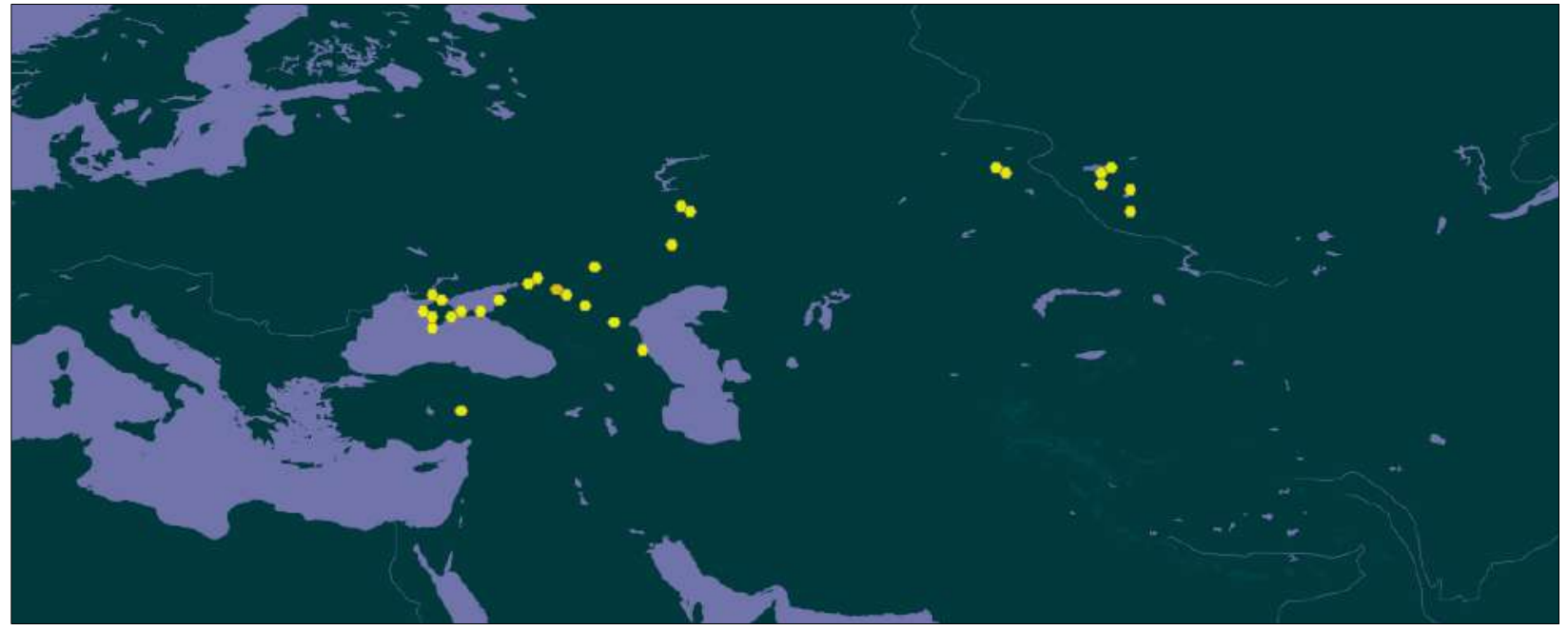

Figure 1. Distribution area of Halimione verrucifera (retrieved from GBIF.org on 2019-03-13).

Due to species rarity in Europe some of extreme western location e.g. those from Romania are excluded from the distribution maps (Fig. 1). In Romania, species distribution includes only inland salt marshes from a few
Eastern counties: Iași, Buzău, Ialomița, Brăila, Constanța, and Tulcea (Fig. 2). From these, the populations from Buzău county represent the westernmost limit of species distribution.

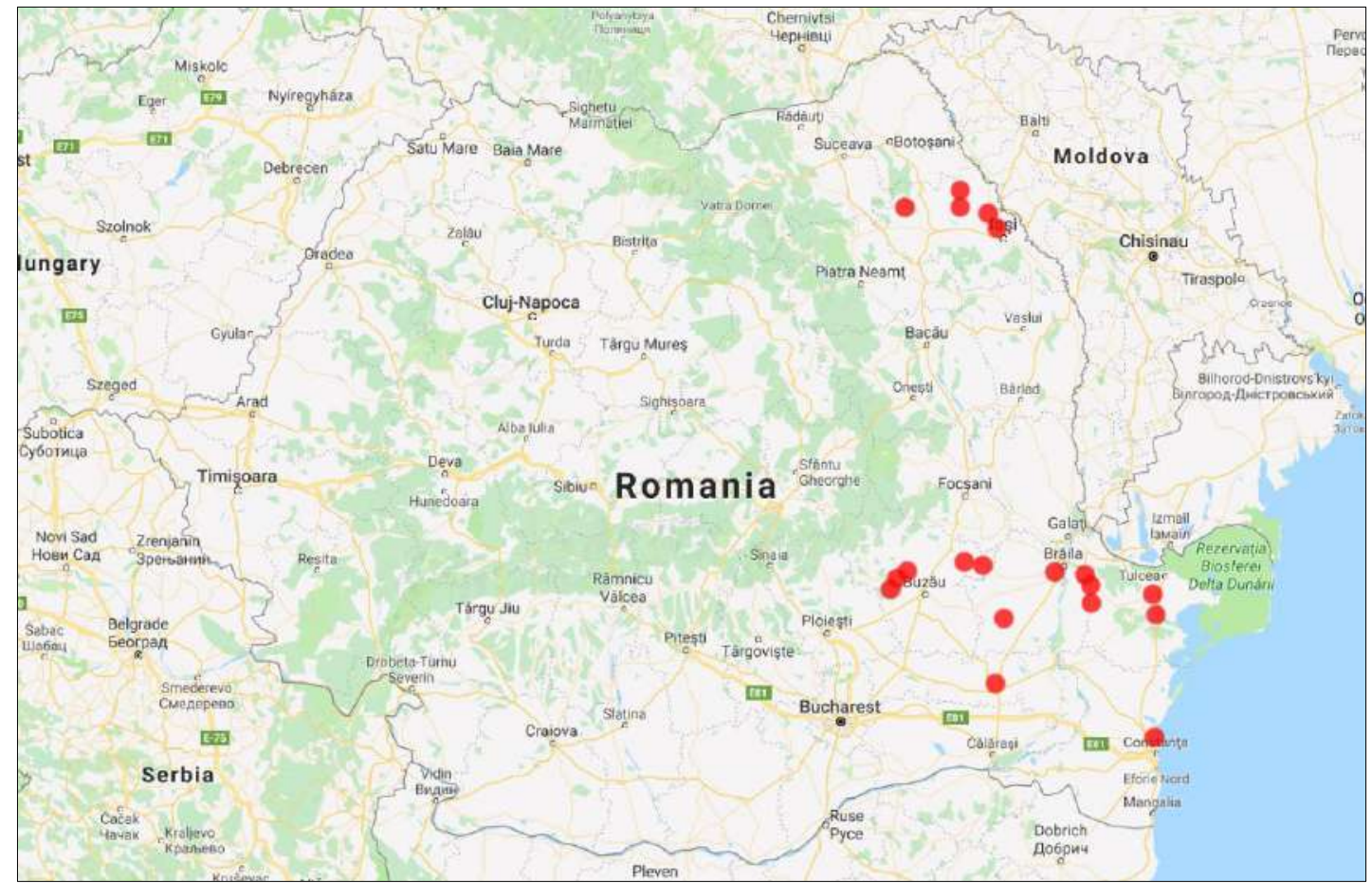

Figure 2. Distribution of Halimione verrucifera in Romania - dots represent locations of documented (Floras or herbarium specimens) populations. 
The investigated population are located onto a Natura 2000 site, named Mud Volcanoes from Pâclele Mari and Pâclele Mici (ROSCI0272), within a habitat of European interest - 1530 Pannonic salt-steppes and salt-marshes. The site is characterized by the geologic phenomenon named "mud volcanoes" - a landform made of mud deposits with salt efflorescence created by a pressurized mud diapir that breaks the Earth's surface resulting in extrusions of hydrocarbon gases, liquid and solid material. The resulting microenvironment is a veritable ecological niche characterised by an extreme saline soil and scarcity of vegetation. Near of the "mud domes" the soil is bare but in their proximity (at 20-50 m) grows only two extreme halophytic plant species: $H$. verrucifera and N. schoberi L. both characteristic from Central Asia flora (Fig. 3).

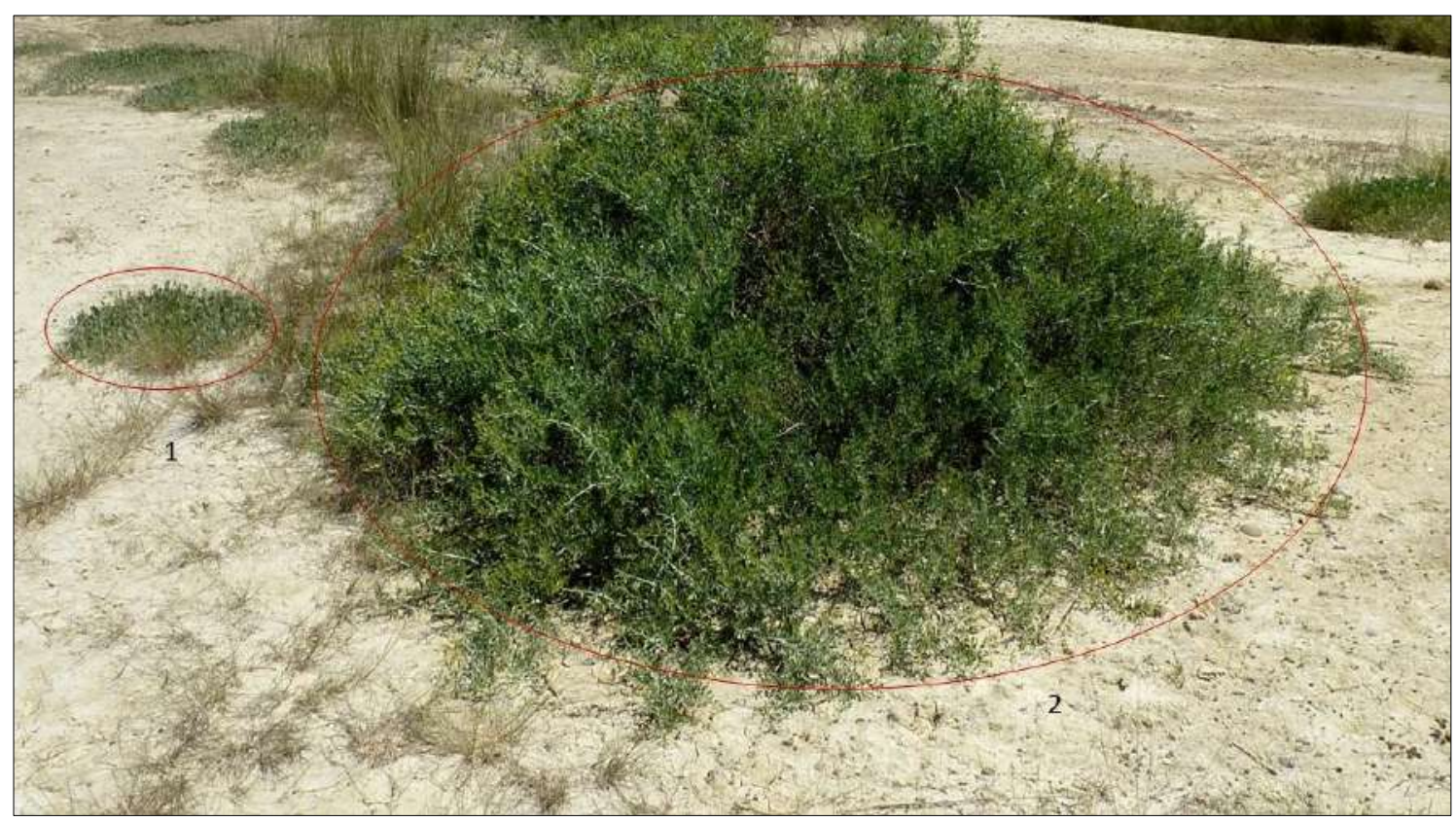

Figure 3. H. verrucifera (1) and N. schoberi (2) in the proximity of mud volcanoes.

The two population of $H$. verrucifera from Mud Volcanoes site, are marginal population for the western distribution range of species. Marginal populations provide the edges for adaptation, evolution and range shifts of plant species, therefore studies of their genetic structure are of particular importance (CHHATRE and RAJORA, 2014). Moreover, representing the westernmost limit of species range, the genetic diversity of these populations reflects evolutionary responses to habitats and also population fitness (YANG et al, 2016).

DNA-based molecular markers are most preferable for plant genetic structure analysis (ROSA et al, 2017) and microsatellites are considered the most suitable for populational genetic variability assessment. Since there are not available microsatellite regions from the genome of $H$. verrucifera a preferable choice is the use of the Intersimple sequence repeat (ISSR) markers (REDDY et al, 2002). The method has the advantage of analysing multiple loci in a single polymerase chain reaction, using longer primers, allowing for more precise annealing and generating a much higher number of polymorphic fragments, compare with RAPD and AFLP. Currently, using ISSR markers is assessed as a reliable, informative, rapid, simple, inexpensive and reproductible method for studies on population genetic diversity (ROSA et al, 2017; BONET and BRANCHARD, 2001; RAKOCZY-TROJANOWSKA and BOLIBOK, 2001).

Despite several studies dedicated generally to halophytes ecology, phytosociology or classification, no studies of population genetics of $H$. verrucifera have yet been published. To our knowledge this is the first assessment of the genetic structure for natural populations of $H$. verrucifera.

Assessing conservation status and consequent preserving in situ populations of $H$. verrucifera are important in the general context of biodiversity preservation and in particular, as host for other species. For example $H$. verrucifera is the larval host for an endemic lepidoptera species Chrysoesthia halimionella described from Ukraine (BIDZILYA and BUDASHKIN, 2015).

Halophytes are important in recycling saline agricultural wastewater and also in reclaiming salt-affected soil in arid-zone irrigation districts (GLENN et al, 1999). Salt-tolerant plants, are sources of valuable secondary metabolites for healthy products as functional foods, nutraceuticals or active principles with potential economic value in several industries (BOESTFLEISCH et al, 2014; KSOURI et al, 2012). 
The aim of the present study was to assess the genetic diversity of the marginal populations from the westernmost limit of species distribution in order evaluate population fitness, adaptative potential and subsequent conservation status.

\section{Materials and Methods}

\section{Plant material}

Leaf material was collected from a total of 66 individuals from the two marginal populations of $H$. verrucifera from the westernmost distribution limit. 31 individuals were sampled from the population from Pâclele Mari and 35 individuals from the population from Pâclele Mici. The two populations are completely separated by the orography of the terrain and at a distance of about $2 \mathrm{~km}$. All the collected fresh leaves were frozen and stored at $-20^{\circ} \mathrm{C}$ until DNA extraction. As outlier dried leaves of Halimione portulacoides (L.) Aellen were used, from the Herbarium collection of the Institute of Biology Bucharest (BUCA, No. 16835).

\section{DNA extraction}

Total DNA was extracted from $100 \mathrm{mg}$ of leaf tissue using a MACHEREY-NAGEL plant kit (\#740770.250) for plant genomic DNA isolation. Both concentration and quality of DNA were assessed using a NanoDrop 1000 spectrophotometer.

\section{PCR amplification and electrophoresis}

Some individual DNA samples chosen to be representative for all the collected material were initially screened with 45 ISSR primers from the UBC primer set no. 9 (Biotechnology Laboratory, University of British Columbia). Six of these primers (UBC no. 825, 826, 827, $835,856,873$ ) yielded polymorphism by generating clearly distinguished bands and were selected for further PCR amplification. The following PCR setup was used for $15 \mu \mathrm{l}$ reactions: $7.5 \mu \mathrm{l}$ GoTaq Green Master Mix, Promega (contains dNTPs, $\mathrm{MgCl}_{2}$, and Taq DNA polymerase), $0.9 \mu \mathrm{L} \mathrm{DMSO}$, and $0.4 \mu \mathrm{l}$ primer. The amount of total genomic DNA used in the reaction varied according to the quality and concentration assessed after extraction. Generally, 1-6.2 $\mu 1$ of DNA template proved to be enough for a successful amplification. PCR was achieved using an Eppendorf thermal cycler (Mastercycler Gradient) using the following program: initial denaturation for $10 \mathrm{~min}$ at $95^{\circ} \mathrm{C}, 35$ cycles of $30 \mathrm{~s}$ at $95^{\circ} \mathrm{C}, 45 \mathrm{~s}$ at $50^{\circ} \mathrm{C}, 2 \mathrm{~min}$ at $72^{\circ} \mathrm{C}$, and $10 \mathrm{~min}$ at $72^{\circ} \mathrm{C}$ for final extension. Negative controls with water replacing the template DNA were used to monitor for contamination. PCR products were separated by electrophoresis in $1.5 \%$ agarose gels buffered with $1 \mathrm{X}$ TBE at voltage ranging from 3.25 to $4.25 \mathrm{~V} / \mathrm{cm}$ for one hour and 30 minutes. $1 \mathrm{~Kb}$ Plus DNA Ladder (Promega, \#G754A) was used as size marker. PCR products were visualized under GENi Gel Documentation System from SynGene. The bands were identified by image analysis software (Gene Tools software (SynGene, Cambridge, UK, version 4.02).

In order to ensure reproducibility, three samples of each population was amplified and analyzed twice.

\section{Data analysis}

Each band in the ISSR profile was considered as a dominant allele for a given locus. The pattern of the bands was transformed into a binary character matrix with 1 for presence and 0 for absence of a band of a particular position in a lane. In order to estimate genetic diversity parameters, the resulting presence/absence data matrix was analysed using the GenAlEx 6.5 software (PEAKALL and SMOUSE, 2006, 2012). Percentage of polymorphic loci, band frequencies, estimated allele frequencies (p, q), Shannon's Information Index (I) and expected heterozygosity $\left(\mathrm{H}_{\mathrm{E}}\right)$ were calculated assuming the HardyWeinberg equilibrium. The presence/absence data matrix was also used to generate a pairwise genetic distance matrix for binary data which was visualized using a cluster analysis (unweighted pair-group method with arithmetic averages, UPGMA) and illustrated in a dendrogram using MEGA version 6 (TAMURA et al, 2013). The genetic structure and variability among the populations was investigated using the non-parametric Analysis of Molecular Variance (AMOVA). The AMOVA analysis was carried out from the distance matrix based on the binary data using the software GenAlEx 6.5. The variance components were tested statistically by randomization tests with 999 permutations. Average Nei's genetic distance between the two populations was also calculated based on estimated allele frequencies data. A Principal Coordinates Analysis (PCoA) was performed using the pairwise genetic distance matrix to visualize the main clusters of individuals.

\section{Results}

\section{Scored bands}

The six ISSR primers generated a total of 86 clear and distinct bands ranging from 230 to $2000 \mathrm{bp}$. A number of 76 of these bands representing $88.37 \%$ of total bands, were species specific when compared with $H$. portulacoides. The total number of scored bands varied from 13 for primer UBC827 to 23 for primer UBC826 with a mean of 14.33 bands per primer (Table 1). 
Table 1. Total number of scored bands generated for selected primers

\begin{tabular}{|c|c|c|c|c|c|c|}
\hline \multirow{2}{*}{ Primer } & \multirow{2}{*}{ No. of loci } & \multicolumn{2}{|c|}{ No. of polymorphic loci } & \multicolumn{2}{c|}{ \% polymorphic loci } & Size of PCR products \\
\cline { 3 - 6 } & & PM & pm & PM & pm & (bp) \\
\hline UBC825 & 13 & 6 & 13 & $46.15 \%$ & $100.00 \%$ & $230-1730$ \\
\hline UBC826 & 22 & 20 & 7 & $86.95 \%$ & $31.81 \%$ & $245-1840$ \\
\hline UBC827 & 9 & 7 & 6 & $77.77 \%$ & $66.66 \%$ & $250-1620$ \\
\hline UBC835 & 14 & 13 & 8 & $92.85 \%$ & $57.14 \%$ & $310-2000$ \\
\hline UBC856 & 16 & 12 & 2 & $75.00 \%$ & $12.50 \%$ & $270-1800$ \\
\hline UBC873 & 12 & 11 & 3 & $91.66 \%$ & $25.00 \%$ & $300-1730$ \\
\hline
\end{tabular}

\section{Genetic diversity}

Shannon's Information Index was calculated as $\mathrm{I}=-1 *(\mathrm{p} * \ln (\mathrm{p})+\mathrm{q} * \ln (\mathrm{q}))$. The average Shannon Information Index was 0.351 at the population level for Pâclele Mari, and 0.233 for Pâclele Mici respectively. The average expected heterozygosity $\left(\mathrm{H}_{\mathrm{E}}\right)$ was estimated to be 0.235 within the population of Pâclele Mari, and
0.157 for Pâclele Mici. An ISSR based UPGMA dendrogram was constructed based on the genetic distance matrix including the outlier. The UPGMA clearly distinguishes the two groups corresponding to the two populations. The outlier, H. portulacoides, occupies a separate branch in the dendrogram (Fig. 4).

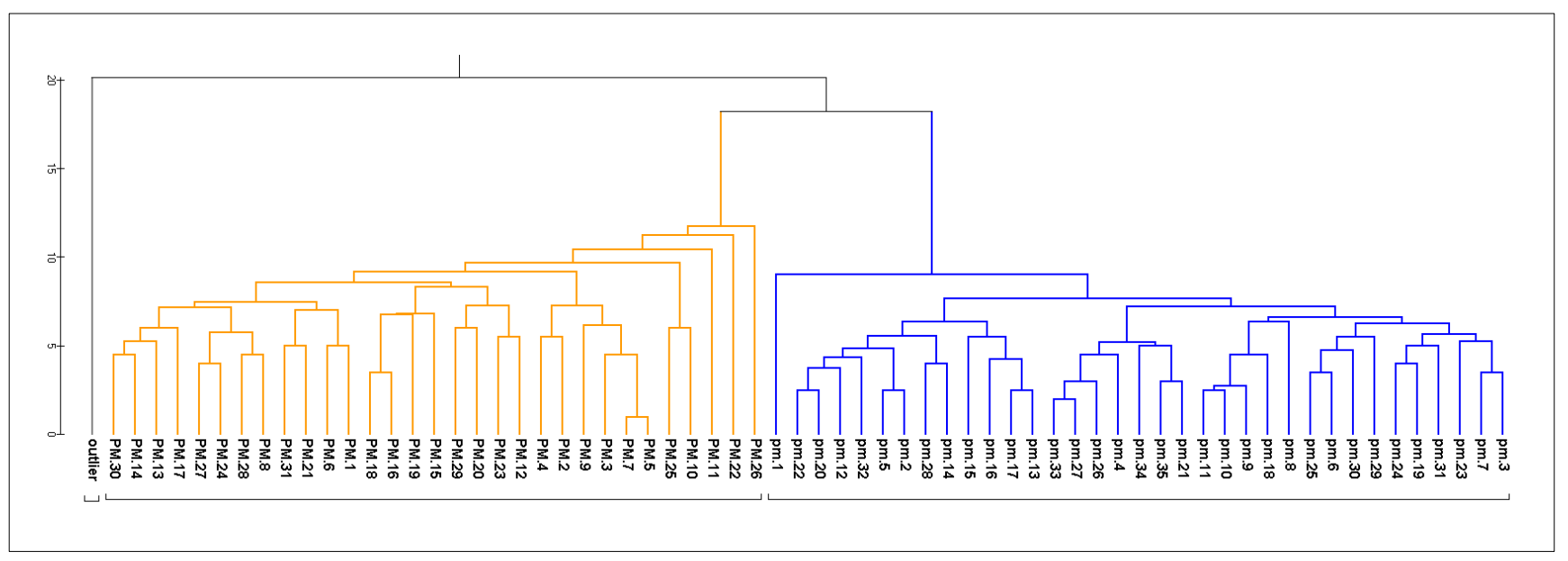

Figure 4. Dendrogram showing genetic relationships of 67 Halimione accessions based on ISSR data (PM - Pâclele Mari samples, pm - Pâclele Mici samples).

The two major groups of individuals corresponding to the two populations can also be observed in a PCoA displayed on a two-dimensional plot (Fig. 5). To assess variability in the data set, through the original genetic distance values were automatically converted through the GenAlEx software to eigenvalues and eigenvectors. The input data, represented by the genetic distance values in a distance matrix, was analysed using a distance standardized method of analysis. The eigenvectors being scores which provide the coordinates of the ordination plot. 


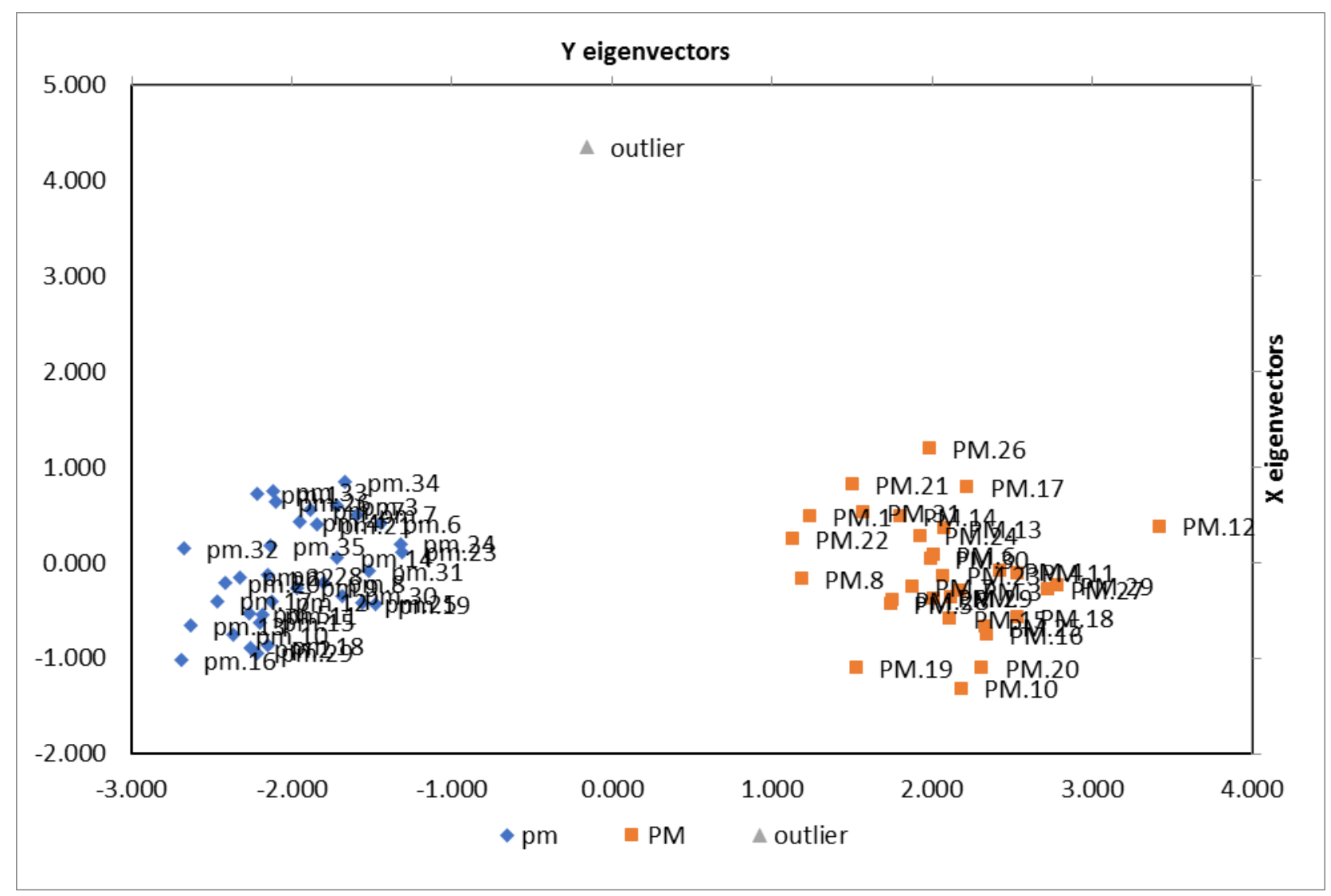

Figure 5. Principal Coordinates Analysis using the genetic distances from 67 individuals (PM - Pâclele Mari cluster, pm - Pâclele Mici cluster).

\section{Genetic relatedness among populations}

The AMOVA partition reveals highly significant population differentiation $(\mathrm{P}<0.001)$, with $56 \%$ of genetic variation residing among populations and $44 \%$ within populations. Nei's Average Genetic Distance between the two populations is 0.195 .

\section{Discussion and Conclusions}

Plant populations are not random made collections of genotypes but are structured and shaped in space and time (LOVELESS and HAMRICK, 1994). Genetic variation in a population is a result of a long-term selection of genes and both spatial and temporal survival depends on genes adaptability in a challenging environment. An increased genetic variation raises the potential to adapt and respond to environmental changes. Our results revealed for both populations an average heterozygosity level that could ensure sufficient genetic polymorphism for species survival in space and time. Particularly important in determining genetic structure are factors influencing reproduction and dispersal (LOVELESS and HAMRICK, 1994). The heterozygosity within population from Pâclele
Mici is lower compared with those from Pâclele Mari and could be explained by the reduced population size favouring a higher inbreeding frequency. Furthermore, it is possible the reduced heterozygosity could be the result of random processes, such as genetic drift and bottleneck effect, due to the small number of individuals, by producing a loss of genetic variation within both populations ova short period of time.

Genetic diversity among populations shows the differences in allele and genotype frequencies between populations. All evaluated indices (AMOVA partition, UPGMA dendrogram, Nei's Average Genetic Distance between the two populations and Principal Coordinates Analysis) showed that populations are clearly separated and with reduced gene flow by pollen and seeds. The PCoA analysis in particular was used to confirm the accuracy of genetic distance values used as input in all evaluated indices. The two main axes were represented in the plot, with a cummulative percentage of variation of $63.12 \%$ explained, separating the two clusters corresponding to the two populations analysed and highlighting the individuality of the outlier. This individuality is due 
to detecting species-specific loci when analyzed with the selected 6 primers from the UBC primer set.

Because of the specific conditions from the ecological niche Mud Volcanoes, species could reach its western distribution limits but due to poor connectivity with other populations is less genetically diverse. Moreover, marginal populations may also be younger than central populations and may have had less time to accumulate genetic diversity (HEDRÉN et al, 2018). In marginal populations species are more vulnerable to extrinsic factors, which in present climate change conditions, become prevalent. Analyzing genetic diversity in this context, we can conclude that populations are in a good conservation status and with an adaptative potential that could ensure species long-term survival.

\section{Acknowledgement}

The study was funded by project no RO1567IBB08/2019 supported by Romanian Academy. The authors would like to thank the Commission for the Protection of Natural Monuments from Romanian Academy for permission to collect the plant material (No. 3984/ 20.03.2017)

\section{Conflict of Interest}

The authors have no conflict of interest to declare.

\section{References}

1. Atriplex verrucifera M. BIEB. in GBIF Secretariat (2017). GBIF Backbone Taxonomy. Checklist dataset https://doi.org/10.15468/39omei (accessed via GBIF.org on 2019-03-13)

2. BIDZILYA, O.V., BUDASHKIN, Y.I. (2015). New species of Gelechiidae (Lepidoptera) from Ukraine. Zootaxa, 3974(2): 217-230.

3. BORNET B, BRANCHARD M. Non-anchored intersimple sequence repeat (ISSR) markers: reproducible and specific tools for genome fingerprinting. Plant Mol Biol Rep, 19 (2001) 209-215. https://doi.org/ 10.1007/BF02772892

4. CHHATRE VE, RAJORA OP. Genetic Divergence and Signatures of Natural Selection in Marginal Populations of a Keystone, Long-Lived Conifer, Eastern White Pine (Pinus strobus) from Northern Ontario. PLoS ONE. 9(5) (2014) e97291. https://doi. org/10.1371/journal.pone.0097291

5. GLENN E.P., BROWN J.J., BLUMWALD E. (1999). Salt tolerance and crop potential of halophytes. Critical reviews in plant sciences, 18(2): 227-255 https://doi.org/10.1080/07352689991309207

6. HEDRÉN M., NORDSTRÖM OLOFSSON S., PAUN O. (2018). Orchid colonization: multiple parallel dispersal events and mosaic genetic structure in Dactylorhiza majalis ssp. lapponica on the Baltic island of Gotland, Annals of Botany, 10.1093/aob/ mcy111

7. KSOURI R., KSOURI W. M., JALLALI I., DEBEZ A., MAGNÉ, C., HIROKO I., ABDELLY, C. (2012). Medicinal halophytes: potent source of health promoting biomolecules with medical, nutraceutical and food applications. Critical reviews in biotechnology, 32(4): 289-326.

8. LOVELESS M.D., HAMRICK J.L. (1984). Ecological determinants of genetic structure in plant populations. Annual review of ecology and systematics, 15(1): 65-95.

9. PEAKALL R, SMOUSE PE. GenAlEx 6.5: genetic analysis in Excel. Population genetic software for teaching and research-an update. Bioinformatics, 28 (2012) 2537-2539. https://doi.org/10.1111/j.14429993.1978.tb01167.x

10. PEAKALL R \& SMOUSE PE. GENALEX 6: genetic analysis in Excel. Population genetic software for teaching and research. Mol Ecol Notes, 6 (2006) 288-295. https://doi.org/10.1111/j.1471-8286.2005.01155.x

11. RAKOCZY-TROJANOWSKA M \& BOLIBOK H, 2004. Characteristics and a comparison of three classes of microsatellite-based markers and their application in plants. Cell Mol Biol Lett, 9: 221-238

12. REDDY MP, SARLA N, SIDDIQ EA, 2002. Inter Sample Sequence Repeat (ISSR) polymorphism and its application in plant breeding. Euphytica, 128: 9-17. https://doi.org/10.1023/A:1020691618797

13. ROSA JD, WEBER GG, CARDOSO R, GÓRSKI F, DA-SILVA PR, 2017. Variability and population genetic structure in Achyrocline flaccida (Weinm.) DC., a species with high value in folk medicine in South America. PLoS ONE, 12(8): e0183533. https://doi.org/10.1371/journal.pone.0183533

14. SUKHORUKOV A.P., NILOVA M.V., KRINITSINA A.A., ZAIKA M.A., ERST A.S., SHEPHERD, K.A., 2018. Molecular phylogenetic data and seed coat anatomy resolve the generic position of some critical Chenopodioideae (Chenopodiaceae-Amaranthaceae) with reduced perianth segments. PhytoKeys, 109: 103.

15. TAMURA K, STECHER G, PETERSON D, FILIPSKI A \& KUMAR S. MEGA6: Molecular Evolutionary Genetics Analysis version 6.0., Mol Biol Evol, 30 (2013) 2725-2729. https://doi.org/10.1093/ molbev/mst197

16. YANG A. DICK WC, YAO X, HUANG H. 2016. Impacts of biogeographic history and marginal population genetics on species range limits: a case study of Liriodendron chinense. Sci Rep, 6: 25632. https://doi.org/10.1038/srep25632 